\title{
Editorial
}

\section{Ingeniería y Competitividad: logros y retos}

Los constantes retos que enfrenta la generación y transferencia de conocimiento en Colombia y en el mundo en general han obligado a la sociedad y en particular a la comunidad científica, a involucrarse de manera cada vez más comprometida con el aporte del conocimiento hacia una sociedad igualitaria y de oportunidades.

La revista inicio su publicación con artículos cuyos autores en su mayoría pertenecían a la Facultad de Ingeniería de la Universidad. En el año de 1997 con seis artículos y 12 autores (66\% autores internos), actualmente ad portas de cumplir 19 años de labores, se han publicado aproximadamente 340 artículos científicos y tecnológicos, el porcentaje de participación de autores internos se ha revertido, a tal punto que en promedio del $30 \%$ de autores es de la Universidad del Valle, el $70 \%$ restante pertenece a instituciones externas (nacionales e internacionales) lo que además de generar una mayor dinámica en el intercambio y la difusión del conocimiento científico, también atiende los diferentes lineamientos y políticas de los índices de indexación a los cuales pertenece la revista, a los que aspira pertenecer y que constituyen un ítem de evaluación para cualquier publicación.

Desde el año 2012 uno de los objetivos propuesto fue la inclusión de la Revista en otras bases de datos de indexación que permitan aumenta la visibilidad de la Revista, estos procesos requieren que la revista cumpla múltiples requisitos e involucran indispensablemente calidad desde el punto de vista editorial y de los artículos. La revista ha fortalecido los procesos de calidad y ha obtenido, en el 2015, el ingreso a la base de datos de Scielo Colombia y por ende en el corto plazo en el Scielo Citation Index (Web of Science/Thomson Reuters).

En el marco de la elaboración del plan de desarrollo de la Facultad de Ingeniería y de la Universidad, se prevé un posicionamiento de la Revista a nivel regional, nacional, e internacional a través de su incorporación en las bases de datos de corriente principal (Scopus e ISI), así como en los nuevos índices de medición con el uso de herramientas de la web; conservando la identidad de la Revista en cuanto a acceso y calidad en el fomento y transferencia del conocimiento, generado en Colombia pues es evidente que la problemática local tiene influencia global y la interacción en la comunidad científica no debe tener límites.

La Revista reconoce la importancia de tener un modelo de medición en el contexto nacional que tenga en cuenta las características de las revistas científicas técnicas y su impacto regional, nacional e internacional y que consideren las nuevas tendencias sobre visibilidad y uso de información, lo que implica aspectos adicionales a la citación de los artículos, por ello mantendrá la CALIDAD en todos los procesos de la publicación de la Revista como factor diferenciador en el trabajo diario a fin de conseguir los objetivos propuestos.

\author{
Fiderman Machuca-Martínez \\ Editor-Jefe \\ Revista Ingeniería y Competitividad \\ Universidad del Valle \\ Cali, Colombia
}

